\title{
Introduction
}

\section{Future management of heart failure}

The papers in this supplement have been prepared following a symposium entitled "The Future Management of Heart Failure" at the British Cardiac Society annual meeting on 24 May 1999. This session focused on the exciting and compelling new evidence about the role of $\beta$ blockers in the management of chronic heart failure (CHF).

Professor Henry Dargie, chairman of the scientific committee of the second cardiac insufficiency bisoprolol study (CIBIS II), presents an overview of the recent randomised controlled trials with $\beta$ blockers in $\mathrm{CHF}$, particularly CIBIS II (page IV2).

Professor Martin Kendall, from Birmingham, UK, draws attention to the impressive effect of $\beta$ blockers on sudden death in CIBIS II and the metoprolol randomised intervention trial in heart failure (MERIT-HF) and points out that the same sort of benefit was observed in the postinfarction trials (page IV5). Professor Kendall highlights the importance of sudden death as the major cause of fatality in patients with milder $\mathrm{CHF}$, and the importance of preventing sudden death in these patients. Professor Kendall goes on to develop the interesting hypothesis that $\beta_{1}$ selective and lipophilic $\beta$ blockers may best achieve this. We do, however, need to see the results of comparative trials, such as the carvedilol or metoprolol European trial (COMET), before this hypothesis is tested.
Professor Richard Hobbs from Birmingham challenges us to think about how we put the evidence for $\beta$ blockers into practice (page IV8). Both he and Professor Dargie seem to see the $\beta$ blocker era as an opportunity to review the whole way in which CHF is managed. Can this be done better? And how? Professor Hobbs makes the critical point that $\mathrm{CHF}$ is too common, disabling, costly, and deadly for the best possible care not to be provided.

Professor Mo Malek from St Andrew's University, UK, takes up the issue of cost (page IV11). He points out just what a huge economic burden $\mathrm{CHF}$ is and how hospital admissions are the major component of that. $\mathrm{He}$ postulates that, not surprisingly, the reduction in hospital admissions, with active treatment, reported in CIBIS II is likely to make bisoprolol a very cost effective treatment for CHF.

Finally, I conclude with an evidence based overview of the three major reports on the effect of $\beta$ blockers on mortality in CHF (page IV14).

I hope you find the issues raised in this supplement thought provoking and interesting. Clearly, we are entering a new era in $\mathrm{CHF}$ treatment. The challenge to apply the evidence that is available to the benefit of our patients.

J J V MCMURRAY Symposium Chairman and Guest Editor

Publication of this supplement was made possible by an educational grant from Merck KGaA, Darmstadt, Germany 